\title{
Long-Term Neurological Effects of Bone Marrow Transplantation in a Canine Lysosomal Storage Disease
}

\author{
ROBERT M. SHULL, MICHAEL A. BREIDER, AND GEORGE C. CONSTANTOPOULOS \\ Department of Pathobiology, College of Veterinary Medicine, University of Tennessee, Knoxville, Tennessee \\ 37916 [R.M.S., M.A.B.]; and the National Institute of Neurological and Communciative Disorders and Stroke, \\ National Institutes of Health, Bethesda, Maryland 20892 [G.C.C.]
}

\begin{abstract}
A naturally occurring disease in Plott hound dogs, caused by deficiency of the lysosomal enzyme $\alpha$-Liduronidase, was used to study the feasibility of bone marrow transplantation therapy in a neurodegenerative storage disease. Three long-term survivors of transplantation with littermate marrow at 5 months of age (before clinical signs) had CNS enzyme activity, glycosaminoglycan storage, and light microscopic and ultrastructural changes evaluated 594, 628, and 740 days after treatment. Iduronidase activity in small amounts (1-3\% of donor values) was detectable in brain tissue. Cerebrospinal fluid had higher iduronidase activity after transplantation (7$15 \%$ of donor values). Enzyme activity within the CNS resulted in significant reductions in stored glycosaminoglycans and resolution, to a large extent, of light microscopic and ultrastructural lesions observed in affected, untreated littermate control dogs. (Pediatr Res 24: 347-352, 1988)
\end{abstract}

\section{Abbreviations}

BMT, bone marrow transplant(ation)

MPS I, mucopolysaccharidosis type I

TBI, total body irradiation

CSF, cerebrospinal fluid

GAG, glycosaminoglycan

PAS, periodic-acid Schiff

Since Garrod (1) first described the "inborn errors of metabolism" in 1908, more than 200 related conditions have been identified. In about 30 of these diseases a specific enzyme deficiency in the lysosomes of affected cells has been identified (2). An important distinction exists, especially as treatment protocols are evaluated, between those "Iysosomal storage diseases" in which the CNS is involved and those diseases that involve visceral tissues, but spare the brain. The "blood-brain barrier" that exists anatomically at the level of capillary walls within the CNS presents a formidable impediment to the transfer of macromolecules (e.g. enzymes) into the brain (3). Because of this barrier, it is generally believed that enzyme deficiency diseases that involve the CNS and cause mental retardation or other neurological manifestations are less amenable to treatment by transplantation or specific enzyme infusion therapy. Although emerg-

Received December 22, 1987; accepted May 11, 1988.

Correspondence Dr. Robert Shull, Department of Pathobiology, A201 Veterinary Medicine Teaching Hospital, University of Tennessee, Knoxville, TN 37916

Supported in part by Research Grants AM32126 and DK38857 from the National Institute of Diabetes and Digestive and Kidney Diseases. ing recombinant DNA biotechnology will potentiate corrective gene therapy for enzyme deficiency diseases, the question of applicability of such treatment for diseases with a neurodegenerative component must be assessed.

BMT has recently been proposed as treatment for certain inherited, metabolic diseases including the mucopolysaccharidoses (4). In contrast to other transplantation procedures, BMT results in donor cells gaining access to multiple anatomic sites in the transplant recipient. It is unclear if BMT will result in beneficial effects within the CNS of patients with neurodegenerative metabolic diseases. We have used a canine model MPS I, a disease in humans $(5)$ and dogs $(6,7)$ caused by deficiency of the lysosomal enzyme $\alpha$-L-iduronidase (EC 3.2.1.76, herein referred to as iduronidase), to assess the benefits of BMT on the biochemical and ultrastructural lesions in dogs with this neurodegenerative disorder.

\section{MATERIALS AND METHODS}

Subjects for this study were from a family of Plott hound dogs affected with MPS I. Although not absolutely identical to any of the three previously described subtypes of MPS I in man, affected dogs have lesions within the brain that are similar to those seen in Hurler disease, the most severe of the human phenotypes (8). After 7.5 Gy TBI, five MPS I-affected dogs were given a BMT from tissue matched littermates (9). In two of three litters a second MPS I-affected dog was available for parallel study as an untreated control. Three of the five recipients became long-term survivors and are the subjects of this report. Two of these recipients were killed on post-BMT days 628 and 594 at which time both were clinically healthy, and the third dog is alive and well at day 1195. Brain tissue and CSF from the latter dog were collected by biopsy for inclusion in this report.

Tissues for routine histopathological examination were fixed in $10 \%$ buffered neutral formalin, paraffin embedded, sectioned, and strained with hematoxylin and eosin. Full hemisections of cerebral cortex at the level of the interthalamic adhesion and the cerebellum at the level of the pons from each dog were examined. Morphometric analysis of alteration in leptomeningeal thickness between groups was based on 100 independent measurements on each section. Smaller pieces of cerebral gray matter were snap frozen in liquid nitrogen; sections were examined with oil red $\mathrm{O}$, PAS, and Alcian blue stains. For ultrastructural study of brain tissue, specimens of cerebral cortex from the temporal lobes were collected under general anesthesia immediately before euthanasia. Tissues were fixed in $2.5 \%$ glutaraldehyde in $0.1 \mathrm{M}$ cacodyl-

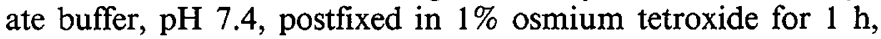
embedded in Epon 812, and examined with a Philips 201 electron microscope after staining with lead citrate and uranyl acetate. 
Tissue and CSF specimens for enzyme and GAG analysis were frozen on dry ice and kept at $-80^{\circ} \mathrm{C}$ until assayed. Iduronidase activity and the GAG content of tissues were measured by previously described methods $(10,11)$. Specimen and substrate blanks were included in all enzyme assays.

Electrophoretic separation of brain GAG was performed on cellulose polyacetate (Sepharose III, Gelman Sciences, Ann Ar-

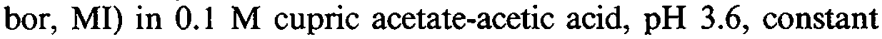
current $0.5 \mathrm{~mA} / \mathrm{cm}$ for $2 \mathrm{~h}$ (12). In each case, GAG equivalent to about $1 \mu \mathrm{g}$ uronic acid was applied to the strips. After electrophoresis in the strips were immersed for $30 \mathrm{~min}$ without prior drying in $0.2 \%$ Alcian blue in $0.05 \mathrm{M}$ magnesium chloride, 0.025 $\mathrm{M}$ sodium acetate, $50 \% \mathrm{vol} / \mathrm{vol}$ ethanol-water, and were destained for $45 \mathrm{~min}$ in a similar solution from which Alcian blue was omitted. GAG were identified by their mobility compared to GAG standards and by their susceptibility to the enzymes chondroitinase $\mathrm{AC}$, chondroitinase $\mathrm{ABC}$, testicular hyaluronidase, and hyaluronidase from Streptomyces hyalurolyticus. Conditions for the enzymatic incubations were those of Breen et al. (13).

\section{RESULTS}

The clinical condition of each long-term survivor was markedly improved and GAG excretion in urine was reduced to near normal levels by month 4 of the posttransplantation period. The most noticeable clinical improvement in each recipient was lack of development of the degenerative joint disease and lameness seen by $9-12$ months of age in both untreated, littermate controls (14). Dogs receiving BMT grew larger than either affected, untreated dog, but remained smaller by $3-5 \mathrm{~kg}$ than the three unaffected donors that weighed $20-27 \mathrm{~kg}$ at maturity. Based on clinical and light microscopic findings, the corneal clouding, which is typical of canine MPS I, was markedly improved in two transplanted dogs and moderately improved in the third. Corneal neovascularization which responded to topical corticosteroid application was seen in each transplant recipient and may have been related to the effects of TBI. Mental development cannot be meaningfully evaluated in canine patients, thus the significance of the biochemical and pathological findings in these dogs must be cautiously interpreted.

In both MPS I-affected control dogs there was marked thickening of the meninges in all sections examined. Cells mainly responsible for this thickening were macrophages and mesenchymal cells resembling fibroblasts, both of which were vacuolated and contained numerous granules causing cytoplasmic distention (Fig. 1). The number of meningeal cell layers in affected dogs was also increased compared to normal dogs. In dogs that received BMT there was considerable reduction in the overall thickness and cellularity of the meninges (Fig. 2). The meninges remained focally hypercellular, but cells were not vacuolated, granulated, or distended with stored GAG. Morphometric analyses of meningeal thickness revealed statistically significant $(p<$ 0.05 ) differences between groups. The mean meningeal thicknesses in two affected controls were 17.1 and $24.4 \mu$; in the two normal dogs, 10.0 and $7.4 \mu$; and in the BMT recipients 7.4 and $11.1 \mu$.

Within the brain parenchyma there were several consistent lesions visible at the light microscopic level in affected, nontransplanted dogs. Astrocytes and microglial cells were increased in number and highly vacuolated giving the parenchyma a fine, moth-eaten appearance (status sponsiosus). Neurons in the cerebral cortex, brain stem, and cerebellum (Purkinje cells) showed variable degrees of fine vacuolation and/or granulation of the cytoplasm that was associated with margination of nuclei. When vacuolated, some neuronal cytoplasms had a decrease in the normal eosinophilic granularity attributable to Nissl substance (chromatolysis). Thick sections (about $1.5 \mu$ ) cut for electron microscopy and stained with toluidine blue most consistently showed the increase in atypical granulation within neurons (Fig. 3).

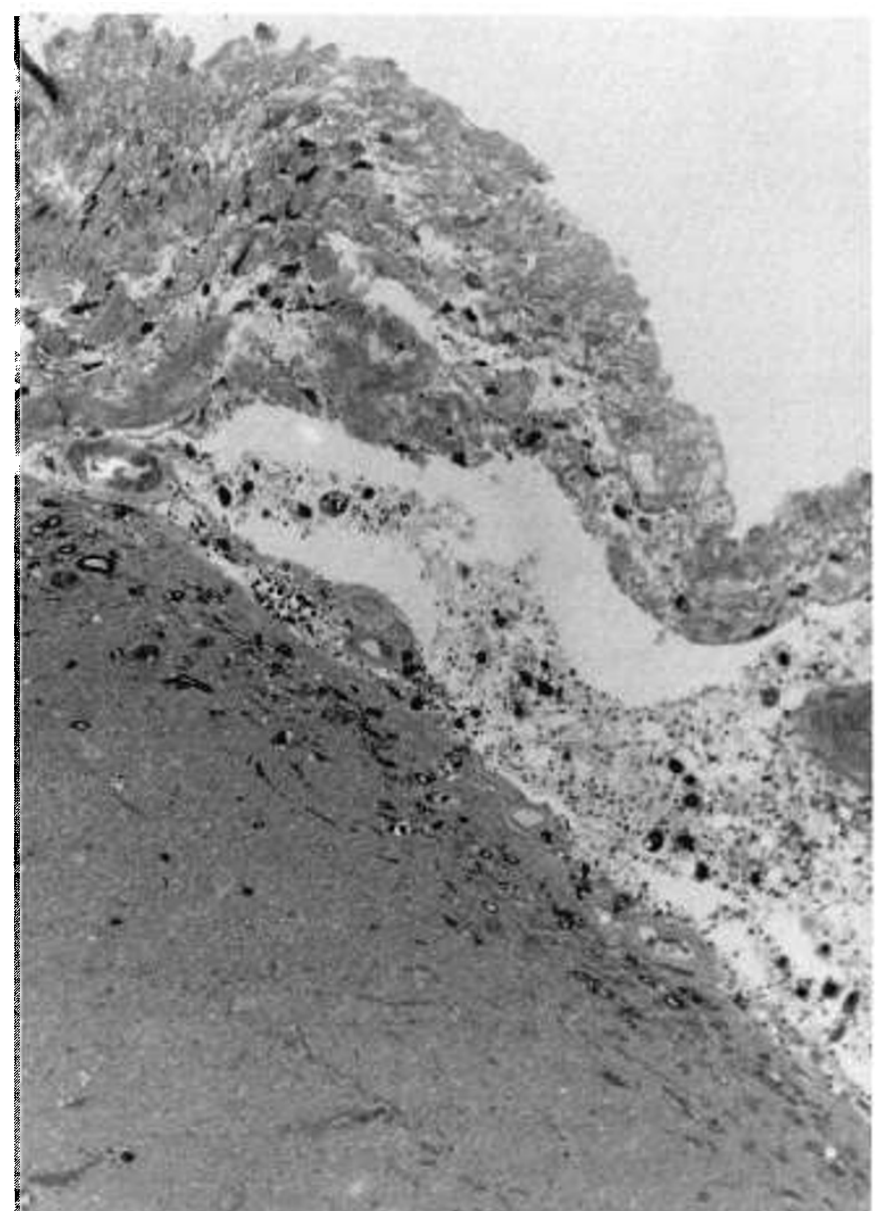

Fig. 1. Meningeal thickening in an nontransplanted, MSP I-affected dog. Marked proliferation of meningeal and phagocytic cells with granulation and vacuolation of most cells is apparent. The cleft between cell layers is artifactual. One $\mu$ section embedded in Epon 812, toluidine blue stain, $\times 490$

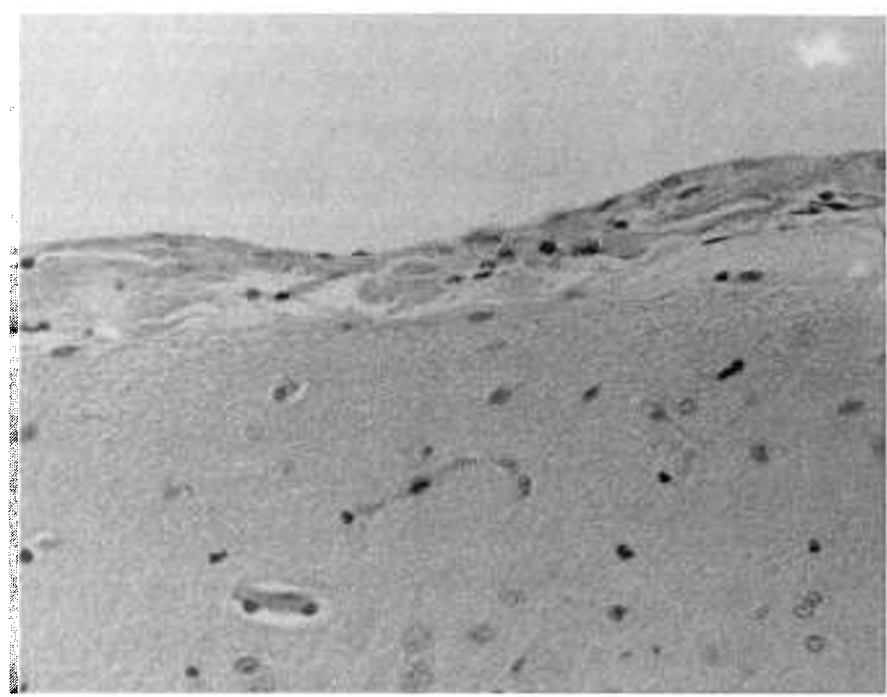

Fig. 2. Typical section of meninges from an MPS I-affected dog 594 days after bone marrow transplantation. The number of cell layers is greatly reduced compared to its littermate, affected control (Fig. 1) and there is no evidence of vacuolation or granulation in meningeal cells. One $\mu$ section embedded in Epon 812, toluidine blue stain, $\times 600$. 


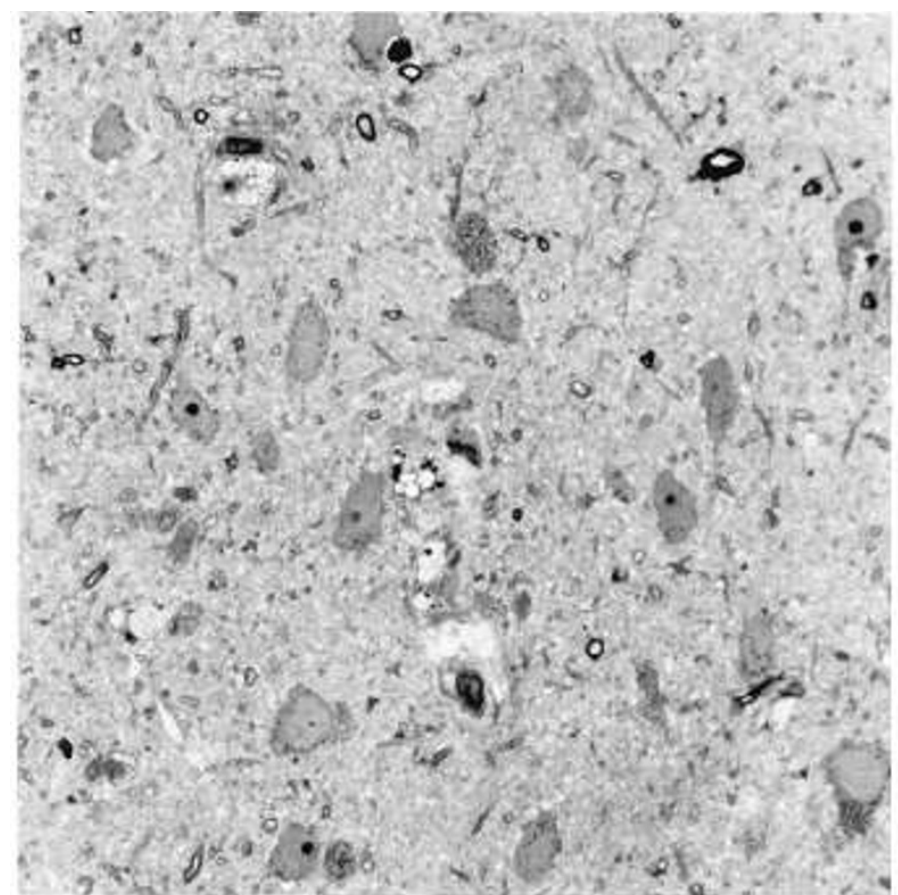

Fig. 3. Cerebral cortex gray matter of a nontransplanted, MPS Iaffected dog. Vacuolation of glial and perithelial cells is responsible for the overall appearance of status sponsiosus seen at lower power. Neurons are slightly distended with a variable amount of dark granulation in their cytoplasm. Granules seen at the light microscopic level were found to be enlarged lysosomes and zebra bodies when seen ultrastructurally. One- $\mu$ section embedded in Epon 812, toluidine blue stain, $\times 750$.

There were several significant differences in cell morphology within the brains of affected, transplanted, and nontransplanted dogs. Despite focal gliosis comparable to untreated dogs, status spongiosus was virtually absent in both BMT recipients due to lack of vacuolation of glial cells. Perithelial cells that lie in approximation to capillaries, but outside the vessel basement membrane, were also of normal morphology. This is in stark contrast to the appearance of these cells in untreated dogs where marked vacuolation was universal. Neuronal cytoplasm in one transplanted dog evaluated postmortem, maintained a degree of granulation in some cells that was greater than that in any of the normal controls. Neurons from the other transplanted MPS I dog were generally smaller with central nuclei and contained much less granulation or vacuolation than either affected, control dog (Fig. 4). In this dog improvement was also apparent in Purkinje cells (cerebellar neurons), whereas in the other transplanted dog these cells were still mildly vacuolated or enlarged. One transplant recipient, which had no evidence of neurologic impairment antemortem, was found to have a diffuse ependymoma extending from the fourth ventricle. The occurrence of this tumor was unrelated to MPS, but may have been a sequela to total body irradiation before BMT.

Histochemcial staining of frozen brain tissue was less revealing than examination of fixed tissue due to less detailed cell morphology being visible. Affected control brain tissue contained the most diffuse Alcian blue and PAS positive material, but it was difficult to interpret deposition within individual cells. Small lipid granules were more easily found in affected control dogs' neurons and glial cells than in those from unaffected or transplanted dogs. Cells from the latter two groups did contain some lipid inclusions and it was impossible to quantitate differences between groups. Similarly, PAS and Alcian blue-positive granules were seen in a small percentage of transplanted and unaffected dogs' cells. Clear differences between groups was not discerned with these stains either.

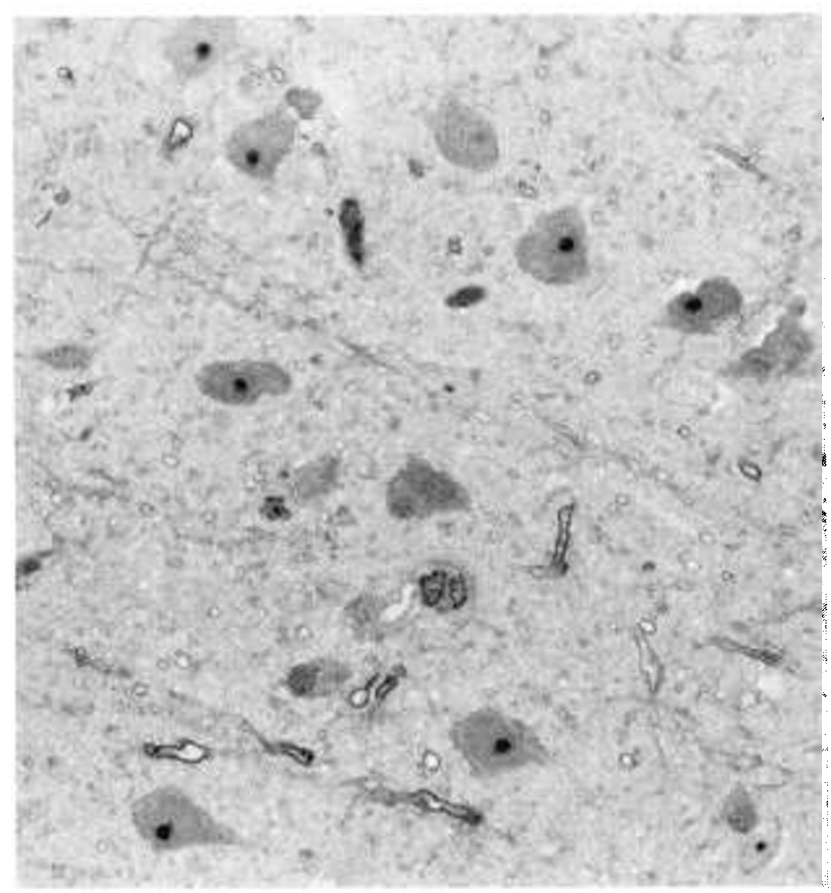

Fig. 4. Cerebral cortex gray matter from a transplanted, MPS Iaffected dog (littermate to dog in Fig. 3). Glial cells lack vacuolation and neurons show only rare granules in their cytoplasm. One- $\mu$ section embedded in Epon 812, toluidine blue stain, $\times 750$.

Ultrastructural changes typical of those in the CNS of both untreated MPS I dogs are shown in Figure 5. Marked lysosomal swelling with coalescence was found in many glial and perithelial cells. Dilated lysosomes contained variable amounts of granular precipitated material that probably represents stored GAG and correlated to the vacuolation-granulation seen at the light microscopic levels. Lysosomes in untreated dogs' neurons, as seen in Figure 5, were less commonly distended than in glial cells, but were more numerous than lysosomes in neurons from donor tissue. Nontransplanted MPS I dogs' neuronal lysosomes often contained lamellar membranous inclusions typical of the "zebra bodies" described in human MPS I and other lysosomal enzyme deficiency diseases (15). Neurons of the three transplant recipients were more variably affected than in the untreated dogs, but as with light microscopy, did not appear completely normal when compared to donor cells. Overall, the number of lysosomes in recipient neurons was reduced compared to the untreated condition, but occasional large, atypical lysosomes persisted (Fig. 6). The most noticeable ultrastructural differences in recipient CNS was the absence of vacuolation of glial and perithelial cells and the near total absence of zebra body formation in neurons.

Changes in iduronidase activity and total GAG content of cerebral cortex gray matter and CSF are presented in Table 1. Accumulation of GAG in brain and CSF is indicative of a neurodegenerative component in this disease; both untransplanted dogs had levels of GAG comparable to previously studied dogs affected with MPS I (7). Brain GAG electrophoresis patterns (Fig. 7) indicated qualitative as well as quantitative changes after BMT. Both dogs that received BMT had electrophoretograms very similar to the normal dog before and after enzymatic digestion with chondroitinase ABC. Brain GAG in the nontransplanted MPS I dog was mainly dermatan sulfate, with a smaller amount of highly fragmented heparan sulfate that resists digestion by chondroitinase $A B C$. In the normal and transplanted dogs a higher percentage of total brain GAG was hyaluronic acid and chondoitin-sulfates 4 and 5 .

The two untreated dogs with MPS had iduronidase activity in both brain and CSF below the sensitivity of the assay which is 


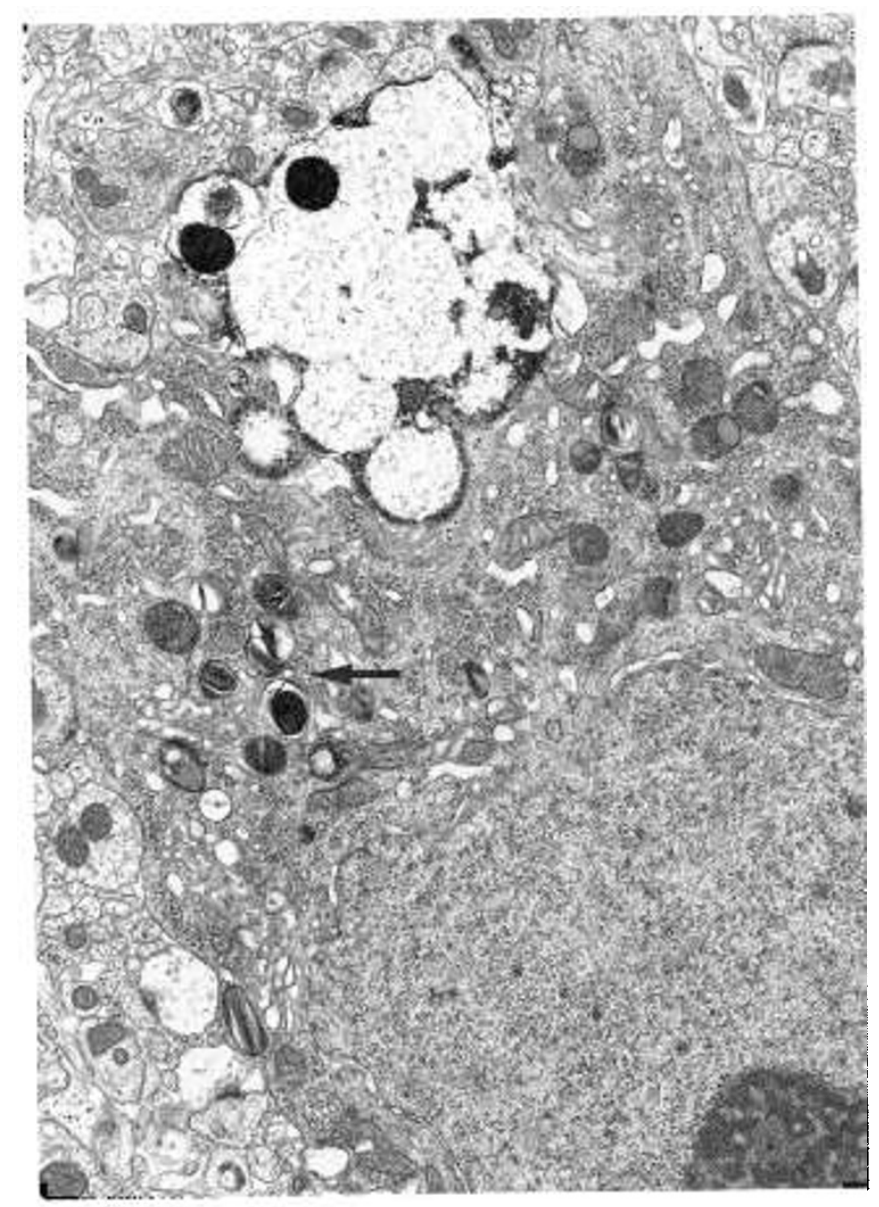

Fig. 5. Electron photomicrograph $(\times 7200)$ of cerebral cortex from a MPS I-affected, untreated dog (litter 2). A highly vacuolated glial cell, its nucleus out of the plane of section, is in contact with a cortical neuron. Vacuolation of the glial cell is the result of distension of lysosomes with stored, granular-appearing GAG causing lysosomal coalescence. Lysosomes in the neuron are excessive in number, but not enlarged. Several of the neuronal lysosomes (arrow) contain lamellar inclusions called zebra bodies that are believed to be the result of metabolic impairment associated with GAG accumulation.

approximately $0.005 \mathrm{nmol} / \mathrm{mg}$ protein/h. Detectable iduronidase activity was present in all brain tissue specimens from transplanted dogs; however, the levels found were only $1-3 \%$ of those in corresponding donor specimens. Inasmuch as no steps were taken to perfuse the tissues of blood cells, some of the activity detected may be from blood leukocytes. BMT was associated with higher levels of iduronidase activity in CSF (which was free of blood contamination), ranging from $7-15 \%$ of donor activity. Enzyme activity in brain and/or CSF was sufficient to cause a reduction in stored GAG. In the two litters with an untreated MPS I dog available for comparison, the mean total brain GAG was reduced by $79 \%$ and the mean CSF GAG by $73 \%$ after BMT. GAG content in each BMT recipient's tissue and CSF was similar to values found in the donor.

\section{DISCUSSION}

Reductions in brain and CSF GAG content appear to be consistent consequences of BMT therapy in canine MPS I. The degree to which morphological changes in neurons and glial cells correlate with metabolic correction is unknown, but would seem to reflect some beneficial effect (enzyme activity) within the brain. It is also unknown how these changes would relate to mental capabilities that, as stated before, cannot be meaningfully evaluated in dogs. When compared to preliminary findings (9), it appears that the clearance of stored GAG increases with time

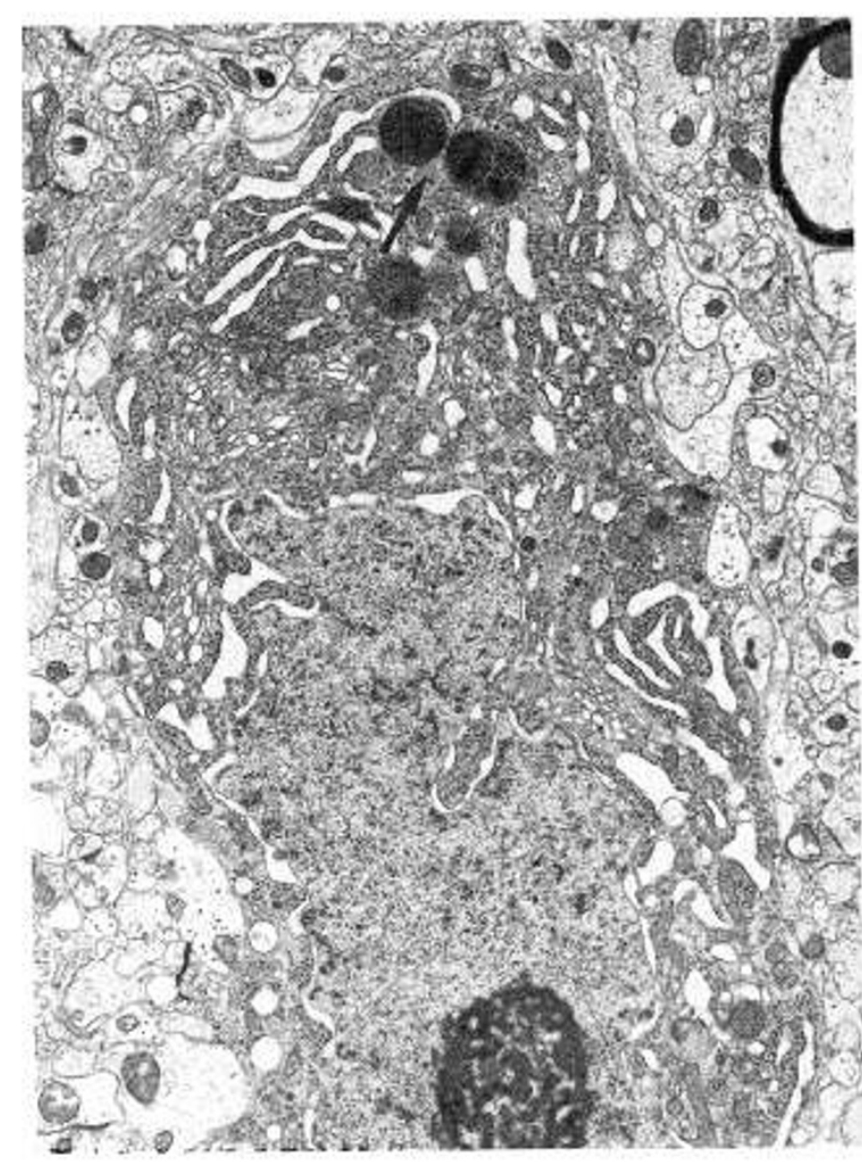

Fig. 6. Electron photomicrograph $(\times 6650)$ of cerebral cortex from a MPS I-affected dog which received a BMT at 5 months of age (litter 2). The tissue was collected at day 594 posttransplantation. Two lysosomes (arrow) appear enlarged, but the overall number of lysosomes in this, and other neurons from the transplanted dogs, was less numerous than in cells from untreated control dogs. Lysosomes in neurons of dogs receiving BMT, including this dog, rarely contained zebra bodies. Glial and perithelial cells (not shown) within the brain parenchyma of dogs which received BMT therapy also had marked reduction in lysosome size, number, and GAG storage compared to their untreated controls.

Table 1. Changes in total GAG and enzyme activity in cerebral cortex and CSF of dogs with MPS I which received littermate $B M T^{*}$

\begin{tabular}{|c|c|c|c|c|c|}
\hline & \multirow[b]{2}{*}{ Litter } & \multicolumn{2}{|c|}{$\begin{array}{l}\text { Iduronidase } \\
\text { activity }\end{array}$} & \multicolumn{2}{|c|}{$\begin{array}{l}\text { Total GAG content } \\
\text { (as uronic acid) }\end{array}$} \\
\hline & & $\begin{array}{l}\text { Brain } \\
(\mu \mathrm{mol} \\
\text { protei }\end{array}$ & $\begin{array}{l}\text { CSF } \\
1 / \mathrm{mg} \\
\mathrm{in} / \mathrm{h})\end{array}$ & $\begin{array}{c}\text { Brain } \\
(\% \text { LFDW }) \dagger\end{array}$ & $\begin{array}{c}\text { CSF } \\
(\mu \mathrm{g} / 100 \mathrm{ml}) \\
\end{array}$ \\
\hline $\begin{array}{l}\text { MPS I, BMT } \\
\text { recipients }\end{array}$ & $\begin{array}{l}1 \\
2 \\
3\end{array}$ & $\begin{array}{l}0.03 \\
0.03 \\
0.01 \ddagger\end{array}$ & $\begin{array}{l}0.16 \\
0.09 \\
0.14\end{array}$ & $\begin{array}{l}0.092 \\
0.095 \\
0.171 \ddagger\end{array}$ & $\begin{array}{l}53 \\
35 \\
55\end{array}$ \\
\hline BMT donors & $\begin{array}{l}1 \\
2 \\
3\end{array}$ & $\begin{array}{l}1.41 \\
0.93 \\
1.26 \ddagger\end{array}$ & $\begin{array}{l}1.09 \\
1.01 \\
2.13\end{array}$ & $\begin{array}{l}0.115 \\
0.079 \\
0.103 \ddagger\end{array}$ & $\begin{array}{l}25 \\
35 \\
37\end{array}$ \\
\hline MPS I, no BMT & $\begin{array}{l}1 \\
2\end{array}$ & $\begin{array}{l}0 \\
0\end{array}$ & $\begin{array}{l}0 \\
0\end{array}$ & $\begin{array}{l}0.380 \\
0.492\end{array}$ & $\begin{array}{l}144 \\
181\end{array}$ \\
\hline
\end{tabular}

* Specimens were collected at the time of necropsy (litter 1, day 628; litter 2, day 594) and by biopsy (litter 3, brain day 273, CSF day 740). Each value is the mean of duplicate assays on two pieces of tissue; intraassay variation was $22 \%$ or less.

$\dagger$ Percent of lipid free dry weight.

$\ddagger$ Previously reported (9); included for completeness. 


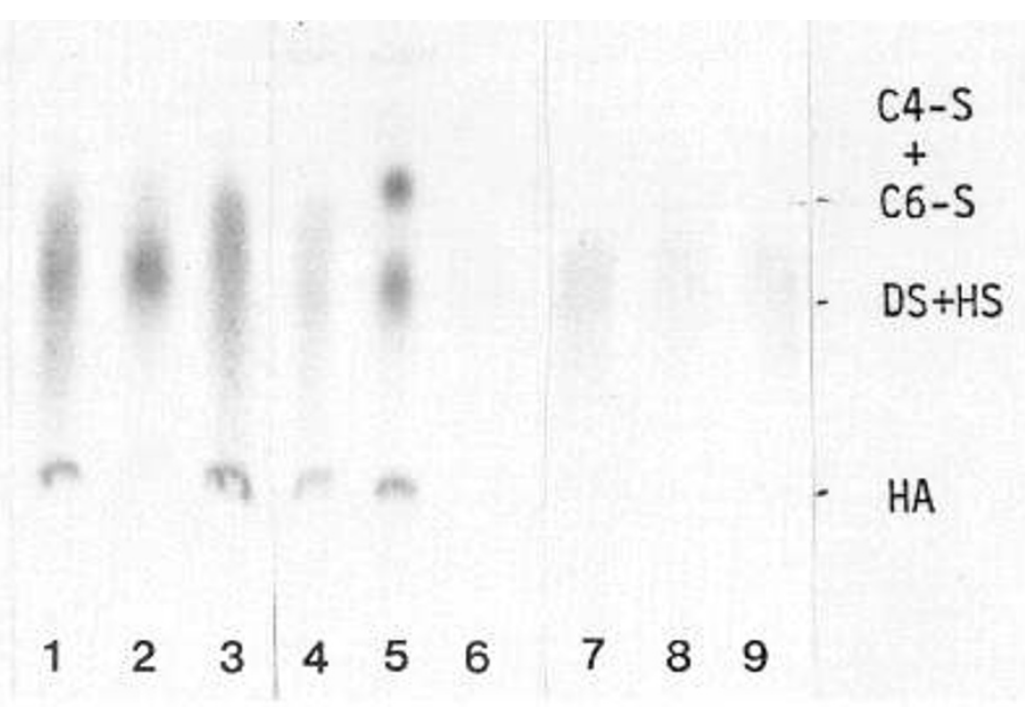

Fig. 7. Cellulose acetate electrophoresis of GAG from canine brain. Specimen 1, normal dog; specimen 2, MPS I-affected control; specimens 3 and 4, MPS I-affected dogs $1 \mathrm{yr}$ and 9 months after BMT; specimen 5, GAG standards; specimen 6 is the same as 4 and 7, 8, and 9 are the same as 1,2 , and 3, but after preincubation with chondroitinase ABC. GAG equivalent to one-fifth the tissue amount of all other dogs were applied to Lanes 2 and 7 (MPS I control) due to the increase in total GAG, dermatan sulfate, and heparan sulfate ( $D S$ and $H S$ ) in that dog. Electrophoretograms from the dogs that received BMT show patterns very similar to the normal dog, before and after incubation with chondroitinase ABC. The weaker bands of hyaluronic acid $(H A)$ and chondroitin sulfates $(C 4-S$ and $C 6-S)$ in the affected control is due to the reduced amount of tissue used for this dog. GAG equivalent to about $1 \mu \mathrm{g}$ uronic acid were electophoresed on cellulose polyacetate as described in "Materials and Methods."

and, thus, recipient 3 , whose brain was last biopsied on posttransplant day 273, may show further reduction in brain GAG when eventually killed. This dog's CSF GAG content on day 740 was comparable to the other two BMT recipients. Each of the three donors was suspected of being a heterozygote based on having intermediate levels of leukocyte and plasma iduronidase activity. The use of heterozygous donors in this project was not considered a liability in that human donors, usually a parent or sibling of the affected child, have a high probability of being heterozygous (i.e. carriers) as the human lysosomal enzyme deficiency diseases are generally recessive traits (16).

Brain tissue iduronidase activity detected posttransplantation was minimal and, were it nor for the corresponding changes in brain GAG content, would be of questionable significance due to the possibility of blood cell contamination. The mechanism by which CNS tissue might acquire iduronidase activity postBMT may involve passage of donor marrow cells across the blood-brain barrier. Evidence exists that perivascular glial cells and microglial cells within the brain are derived from bone marrow precursors (17-20). Bone marrow origin cells have also been reported in a child with metachromatic leukodystrophy after BMT from his sister (21). Other lysosomal storage diseases in which deficient enzyme activity has been partially replaced in the CNS after BMT include human MPS I (4\% donor level) (22), canine fucosidosis (2-21\% donor levels) (23), and murine Krabbe disease (2-15\% donor levels) (24).

The protocol used for preparative marrow ablation before BMT may affect the degree to which enzyme or enzyme-producing cells enter $\mathrm{CNS}$ tissue. Most animal studies implicating bone marrow precursors for CNS phagocytes have involved irradiated subjects $(17,20)$. MPS I dogs received TBI, thus the blood-brain barrier was subjected to a dose of radiation that conceivably could alter, at least temporarily, its permeability. In previous animal (23) and human (21) transplants the cerebral cortex has been completely or partially shielded, but donor cells and enzyme were still able to cross the blood-brain barrier. The importance of the effects of various preparative regimes on CNS changes needs to be considered as BMT protocols for neurodegenerative disease are evaluated.

Increased brain GAG content, seen in all MPS I-affected dogs to date, may reflect excessive storage in a variety of cell types within that tissue. In an attempt to clarify this, light microscopic and ultrastructural studies were performed on cerebral cortex specimens collected concurrently with those for biochemical analysis. Cellular changes associated with increased brain GAG and, more importantly, reduction in tissue GAG in the three transplant recipients were identified. The majority of stored GAG appears to be in meningeal, glial, and perivascular cells; the clearest changes after BMT occurred in these sites. Changes in cortical neurons are of paramount interest because these cells are considered to be least likely to benefit from BMT and are affected in children with the Hurler phenotype of MPS I $(25,26)$. Reduction in lysosome number and, most dramatically, the absence of lamellar deposits in lysosomes (zebra bodies) in one transplanted dog may be indicative of a beneficial effect within neurons. Neurons in the second dog showed less improvement, indicating that the response to BMT may vary among individuals. The mechanism by which neuronal accumulation of a storage product or neuronal metabolism can be altered by BMT is unclear and worthy of further study. Evidence that cells of marrow origin enter the CNS, and that certain cells may secrete and acquire (i.e. share) lysosomal enzymes in vitro (27), makes it attractive to hypothesize that such processes might occur in the CNS after BMT. The present studies, however, shed no light on these mechanisms.

Regardless of the biochemical events involved, these findings in dogs suggest that BMT may be beneficial in some neurodegenerative storage diseases. Recently reported clinical improvement after BMT in six children with MPS IH is encouraging (28). Experience with BMT in humans and dogs adds cautious enthusiasm for the feasibility of specific gene therapy for lysosomal storage diseases. Techniques currently available for the cloning of genes that encode for lysosomal enzymes (29), and the insertion of genetic material into bone marrow stem cells of man (30) and dogs (31) via retroviral vectors, should make evaluation of gene therapy for enzyme deficiency disorders possible in appropriate animal models of human disease.

\section{REFERENCES}

1. Garrod AE 1908 Inborn errors of metabolism. Lancet 2:1-8, 73-82, 145-155, 214-221

2. Galjaard H, Reuser AJJ 1984 Genetic aspects of lysosomal storage diseases. In: Dingle JT, Dean RT, Sly W (eds) Lysosomes in Biology and Pathology. Elsevier, Amsterdam, pp 315-345 
3. Neuwelt EA, Barranger JA, Pagel MA, Quirk JM, Brady RO, Frenkel EP 1984 Delivery of active hexosaminidase across the blood brain barrier in rats. Neurology 34:1012-1019

4. Krivit W, Paul NW 1986 Bone Marrow Transplantation for Treatment of Lysosomal Storage Diseases. Alan R Liss Co, New York, pp 1-53

5. Bach G, Friedman R, Weissman B, Neufeld EF 1972 The defect in Hurler and Scheie syndromes: deficiency of $\alpha$-L-iduronidase. Proc Natl Acad Sci USA 69:2048-2051

6. Spellacy E, Shull RM, Constantopoulos G, Neufeld EF 1983 A canine model of $\alpha$-L-iduronidase deficiency. Proc Natl Acad Sci USA 80:6091-6095

7. Shull RM, Helman RG, Spellacy E, Constantopoulos G, Munger RJ, Neufeld EF 1984 Morphologic and biochemical studies of canine mucopolysaccharidosis I. Am J Pathol 114:487-495

8. Constantopoulos G, Shull RM, Hastings NE, Neufeld EF 1985 Neurochemical characterization of canine $\alpha$-L-iduronidase deficiency disease. J Neurochem 45:1213-1217

9. Shull RM, Hastings NE, Selcer RR, Jones JB, Smith JR, Cullen WC, Constantopoulos G 1987 Bone marrow transplantation in canine mucopolysaccharidosis I. J Clin Invest 79:435-443

10. Rome LH, Weissman B, Neufeld EF 1979 Direct demonstration of binding of a lysosomal enzyme, $\alpha$-L-iduronidase, to receptors on cultured fibroblasts. Proc Natl Acad Sci USA 76:2331-2334

11. Constantopoulos G, McComb RD, Dekaban AS 1976 Neurochemistry of the mucopolysaccharidoses: brain glycosaminoglycans in normals and four types of mucopolysaccharidoses. J Neurochem 26:901-908

12. Stefanovich V, Gore I 1967 A micromethod for determination of acid mucopolysaccharides in vascular tissue. J Chromatogr 31:473-478

13. Breen M, Weinstein HG, Blacik LJ, Borcherding MS, Sittig RA 1976 Microanalysis and characterization of glycosaminoglycans from human tissue via zone electrophoresis. Methods Carbohydr Chem 7:101-115

14. Shull RM, Walker MA 1988 Radiographic findings in a canine model of mucopolysaccharidosis I: changes associated with bone marrow transplantation. Invest Radiol 23:124-130

15. Aleu FP, Terry RD, Zellweger H 1965 Electron microscopy of two cerebral biopsies in gargoylism. J Neuropathol Exp Neurol 14:304-317

16. McKusick VA, Neufeld EF 1983 The mucopolysaccharide storage diseases. In: Stanbury JB, Wyngaarden JB, Fredrickson DS, Goldstein JL, Brown MS (eds) The Metabolic Basis of Inherited Disease. McGraw-Hill, New York, pp 778-787

17. Hickey WF, Kimura H 1988 Perivascular microglial cells of the CNS are bone- marrow-derived and present antigen in vivo. Science 239:290-292

18. Bartlett PF 1982 Pluripotential hematopoietic stem cells in adult mouse brain. Proc Natl Acad Sci USA 79:2722-2725

19. Miyake T, Tsuchihashi Y, Kitamura T, Fujita S 1984 Immunohistochemical studies of blood monocytes infiltrating into the neonatal rat brain. Acta Neuropathol 62:291-297

20. Ting JPY, Nixon DF, Weiner LP, Frelinger JA 1983 Brain la antigens have a bone marrow origin. Immunogenetics 17:295-301

21. Bayever E, Philippart M, Nuwer M, Ladisch S, Brill N, Sparkes RS, Feig SA 1985 Bone marrow transplantation for metachromatic leukodystrophy. Lancet $2: 471-473$

22. Hobbs JR 1985 Correction of 34 genetic diseases by displacement bone marrow transplantation. Plasma Ther Transfus Techol 6:221-246

23. Taylor RM, Farrow BRH, Stewart GJ, Healy PJ, Tivier K 1987 Lysosomal enzyme replacement in neural tissue by allogeneic bone marrow transplantation following total lymphoid irradiation in canine fucosidosis. Transplan Proc 19:2730-2734

24. Hoogerbrugge PM, Poorthuis BJHM, Vossen JMJJ, Dooren $\mathrm{LJ}$, Wagemaker G, van Bekkum DW 1987 Bone marrow transplantation in murine lysosomal storage disease: the neurologically damaged twitcher mouse. Exp Hemato $15: 616 \mathrm{a}$

25. Watts RWE, Spellacy E, Hume Adams J 1986 Neuropathological and clinical correlations in Hurler disease. J Inherited Metab Dis 9:261-272

26. Dekaban AS, Constantopoulos G, Herman MM, Steusing JK 1976 Mucopolysaccharidosis type V (Scheie syndrome). Arch Pathol 100:237-245

27. Abraham D, Muir H, Olsen I, Winchester B 1985 Direct enzyme transfer from lymphocytes corrects a lysosomal storage disease. Biochem Biophys Res Commun 129:417-425

28. Krivit W, Ramsay NKC, Kersey J, Whitley CB 1987 Bone marrow transplantation for lysosomal storage diseases. Exp Hematol 15:580a

29. O'Brien JS, de Wet J, Fukushima H, Wicox E, Dewji N, McGee J, Warner T, Yoshida A, Fluharty A, Hill F, Helinski D 1984 Cloning of lysosomal genes. In: Barranger JA, Brady RO (eds) Molecular Basis of Lysosomal Storage Disorders. Academic Press, Orlando, FL, pp 387-403

30. Hogge DE, Humphries RK 1987 Gene transfer to primary, normal and malignant human hemopoietic progenitors using recombinant retroviruses. Blood 69:611-617

31. Kwok WW, Schuening F, Stead RB, Miller AD 1986 Retroviral transfer of genes into canine hemopoietic progenitor cells in culture: a mode for human gene therapy. Proc Natl Acad Sci USA 83:4552-4555 